\title{
High Temperature Corrosion behavior of Metallic Materials in modified
}

\section{Hitec Molten Salts}

\author{
Wei Zhai ${ }^{1, a}$, Bo Yang ${ }^{1, b}$, Shiping $\mathrm{Li}^{1, \mathrm{c}}$,Zhigang Wang ${ }^{1, \mathrm{~d}}$ Shuanghong Zhang ${ }^{1,}$ \\ e, Guojia Huang ${ }^{1, f}$
}

1 Guangzhou Special Pressure Equipment Inspection and Research Institute, 510100 Guangzhou, China

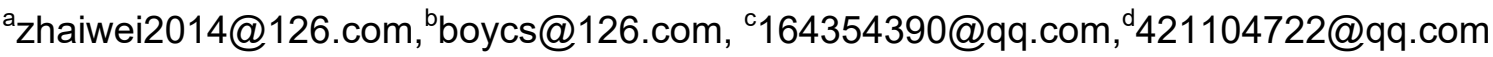

e240092821@qq.com, ${ }^{\mathrm{f}} 409700834 @ q q . c o m$

Keywords: corrosion; metal materials; molten salts; electrochemical tests

\begin{abstract}
High temperature molten salts as a heat transfer heat storage medium has been more widely used in the field of concentrated solar thermal power generation. The metal material in molten salts has strong corrosive, limiting molten salts large-scale industrial use. In this paper, study on corrosion of $321 \mathrm{H}, 304,316 \mathrm{~L}$, P91 metal materials in modified Hitec molten salts. Under the same condition it was found that $316 \mathrm{~L}, 304$ steels corroded at a rate of $35 \%$ less than P91. Spallation of corrosion products was observed on P91 steel, while no obvious observed on other kinds of stainless steel. Corrosion rates of $316 \mathrm{~L}$ and 304 slowly increased with temperature. Oxidation mechanisms little varied with temperature. Corrosion products of metal materials observed at $450^{\circ} \mathrm{C}$ were primarily $\mathrm{Fe}$ oxide and $\mathrm{Fe}, \mathrm{Cr}$ oxide. Electrochemical tests were performed by electrochemical measurement work station. The Nyquist plots of metal materials indicated that the anticorrosive properties of 316L, 304 steels are better than $321 \mathrm{H}$, P91steels. Then the anticorrosive properties of metal materials accordance with corrosion kinetics curve of metal materials.
\end{abstract}

\section{Introduction}

With rapid development in economy and improvement in the standard of living, energy consumption is quite large and the energy shortage problem becomes very severe. Solar energy, a kind of renewable energy, could resolve the energy shortage problem. However, solar thermal power is easily impacted by weather such as cloudy weather and night; therefore, thermal storage technology could be used in order to improve the efficiency of solar thermal power generation[1]. So excellent high temperature heat transfer/storage medium becomes the key to guarantee the normal work of the solar thermal power generation system in the field of concentrated solar thermal power generation. The molten salts has a low melting point, melting heat large, high specific heat capacity, low viscosity, good thermal stability, Wide temperature range, low price and a series of advantages. Molten salts in chemical industry, energy and other fields has been very widely used[2-5].

However, molten salt has strong corrosive to metal equipment and study the molten salt and metal equipment compatibility is very necessary. In addition to good corrosion resistance, no degradation of mechanical properties occurred after long-term isothermal exposure to molten nitrate 
salt[6]. Study on corrosion situation of 316L, 304, 321H, P91 metal materials at high temperature molten salts nitrate in this article. The results for storage tanks, pipelines, valves and related equipment of solar thermal power generation system service life estimation to provide theoretical guidance and technical support.

\section{Procedures}

Specimens were obtained from Metal Samples Company as " $10 \times 15 \times 5$ or $10 \times 10 \times 5$ " mm coupons with a 1200 grit finish. Wash specimens with acetone and ethanol, and then drying to spare. Static immersion tests were performed at the National Solar Thermal Test Facility (NSTTF) located at Laboratories. Exposures were performed at two temperatures $\left(450^{\circ} \mathrm{C}\right)$, which were chosen to reflect different operating conditions within a CSP plant. Test samples were mounted on corundum crucible, then immersed in modified solar two at a given temperature .

Sample is removed every 50 hours, except the first remove. Weight gain and descaled data were determined from this data with guidance from GB/T 25147-2010 standards. Corrosion rates were calculated as follows [10]:

$$
\mathrm{A}=\frac{m_{0}-m_{1}}{S}
$$

A is corrosion amount of metal $\left(\mathrm{mg} / \mathrm{mm}^{2}\right)$;

$\mathrm{m}_{\mathrm{o}}$ is Specimen quality before test $(\mathrm{mg})$;

$\mathrm{m}_{1}$ is Specimen quality after test $(\mathrm{mg})$;

$\mathrm{S}$ is the total surface area of the specimens $\left(\mathrm{mm}^{2}\right)$.

Metal change results were reported from the longest duration exposure time, which was a nominal 420 hours for $450^{\circ} \mathrm{C}$.

Surface morphologies of the dried silicate-coated samples were observed by SEM (PHILIPS, XL-30-FEG, Eindhoven, Holland) as well as atomic force microscopy (JEOL, SPI3800N, Tokyo, Japan). Microscopy was employed to determine relevant corrosion reactions that occurred during exposures. SEM was primarily used with cross section views to determine depth of attack and corrosion structure. Images were generated correlating the presence of an element within a given area.

Electrochemical tests were performed using a CHI640 electrochemical measurement work station (CH Instruments, Inc, Shanghai, China)[11].

Table 1: Composition of metal materials

\begin{tabular}{cccccccccccccccc}
\hline Alloy & $\mathrm{C}$ & $\mathrm{Mn}$ & $\mathrm{Si}$ & $\mathrm{P}$ & $\mathrm{S}$ & $\mathrm{Cr}$ & $\mathrm{Ni}$ & $\mathrm{Mo}$ & $\mathrm{V}$ & $\mathrm{Ti}$ \\
\hline $321 \mathrm{H}$ & $0.04-0.1$ & $2<$ & $1.0<$ & $0.045<$ & $0.03<$ & $17.0-19.0$ & $9.0-12.0$ & - & & - & -0.6 \\
$\mathrm{P} 91$ & 0.11 & 0.46 & 0.31 & 0.015 & 0.0038 & 9.46 & 0.09 & 0.88 & 0.2 & - \\
304 & $0.08<$ & $2<$ & $1<$ & $0.045<$ & $0.03<$ & $18-20$ & $8.0-10.5$ & - & - & - & - & - \\
$316 \mathrm{~L}$ & $0.03<$ & $2<$ & $1<$ & $0.045<$ & $0.03<$ & $16-18$ & $10-14$ & $2-3$ & - & - \\
\hline
\end{tabular}

\section{Results}

Corrosion kinetics curve of metal materials exposed to modified Hitec molten salts for $420 \mathrm{~h}$ at $450^{\circ} \mathrm{C}$ in Figure 1. The figure shows that calculations would predict $0.558 \mathrm{mg} / \mathrm{mm}^{2}$ of P91 metal loss, $0.459 \mathrm{mg} / \mathrm{mm}^{2}$ of $321 \mathrm{H}$ metal loss, $0.387 \mathrm{mg} / \mathrm{mm}^{2}$ of 304 metal loss, $0.329 \mathrm{mg} / \mathrm{mm}^{2}$ of $316 \mathrm{~L}$ metal loss, using linear oxidation kinetics. The kinetic curves of four kinds of metals are similar to parabolic. The rapid corrosion rates of metal materials were observed at the initial stage. Then the corrosion of four kinds of metal materials was found to slow upward trend of weightlessness, 
because the formation of a layer of $\mathrm{Cr}_{2} \mathrm{O}_{3}$ oxide film, delaying the corrosion of the alloy. Observed corrosion rates of $316 \mathrm{~L}, 304$ were found to be consistently lower in comparison to $\mathrm{P} 91$ and $321 \mathrm{H}$ at temperatures of $450^{\circ} \mathrm{C}$. With the extension of time, Cr oxide film of P91 steel was damaged, material loss protection, corrosion degree intensifies. The corrosion incremental of $316 \mathrm{~L}, 304$ stainless steels declined with time. The phenomenon shows that the corrosion film grown of the alloy on the surface has a protective effect and the corrosion film can prevents the further corrosion from proceeding. The $316 \mathrm{~L}, 304$ stainless steels were found to have mild corrosion performance, with overall rates less than $0.56 \mathrm{mg} / \mathrm{mm}^{2}$ for $420 \mathrm{~h}$ at $450^{\circ} \mathrm{C}$.

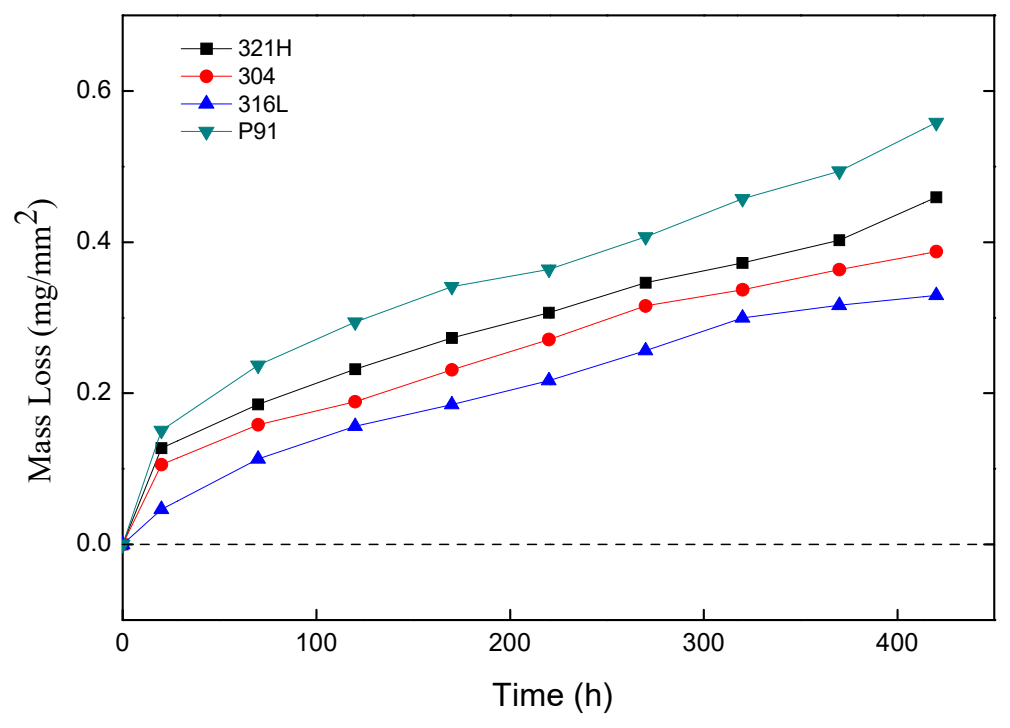

Figure 1. Corrosion kinetics curve of metal materials in the modified

Hitec molten salts at $450^{\circ} \mathrm{C}$

Macro corrosion morphology of metal materials exposed to modified Hitec for $420 \mathrm{~h}$ at $450^{\circ} \mathrm{C}$ in Figure 2. Outstanding surface spallation and eroding pits was not observed on metal materials, but the surface of the metal material appears slight color change.

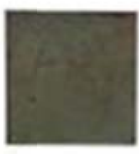

$321 \mathrm{H}$

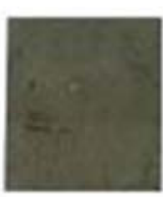

304

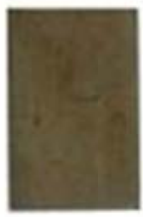

$316 \mathrm{l}$.

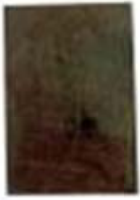

P91

Figure 2. Macro corrosion morphology of metal materials in the modified Hitec molten salts at $450^{\circ} \mathrm{C}$ 

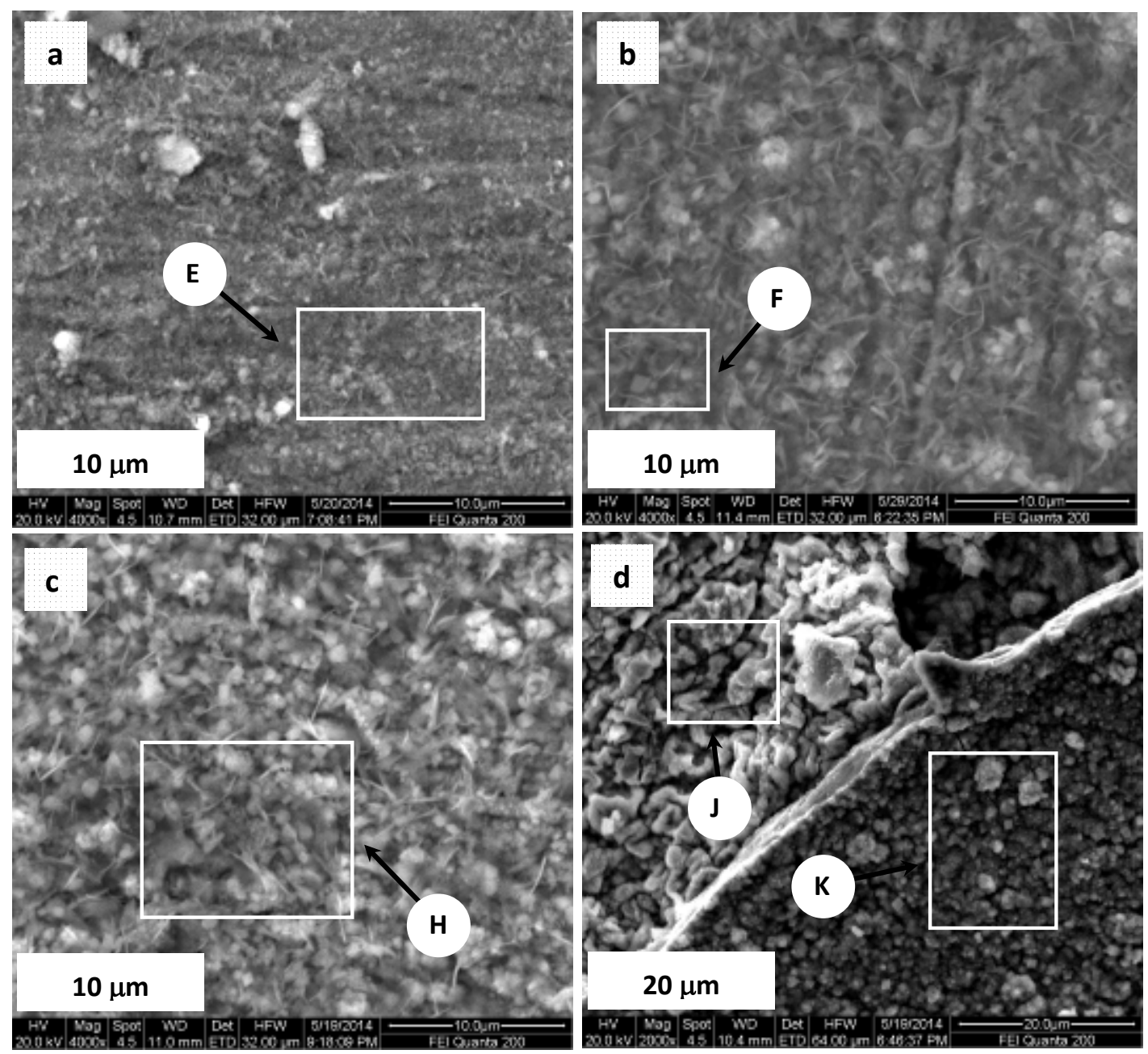

Figure 3. Surface morphologies of metal materials in the modified Hitec molten salts at $450^{\circ} \mathrm{C}(\mathrm{a}-316 \mathrm{~L}, \mathrm{~b}-304, \mathrm{c}-321 \mathrm{H}, \mathrm{d}-\mathrm{P} 91)$

Surface morphologies and EDS X-ray spectra of 316L, 304, 321H and P91steels exposed to modified Hitec for $420 \mathrm{~h}$ at $450^{\circ} \mathrm{C}$ in Figure 3, 4. The surface observation of $316 \mathrm{~L}$ reveals that small amounts of corrosion products are agglomerate and accidented. The $316 \mathrm{~L}$ was found to light corrosion level. It was found through EDS that mainly has $\mathrm{Fe}, \mathrm{O}, \mathrm{Cr}$, $\mathrm{Ni}$ elements and a small amount of Mn element in region E. Ni content increased in the area of the E show that Ni spread outward and $\mathrm{Ni}$ oxide was generated at the oxide film/metal interface.

A small amount of agglomerate corrosion products were present in 304 stainless steel surface. The acicular corrosion products were observed on 304. By SEM / EDS analysis shows, the corrosion products of 304 are mainly $\mathrm{Fe}, \mathrm{Cr}$ or Ni oxide. Migration of chromium spread outside was observed in molten salts systems. The corrosion products of $321 \mathrm{H}$ are mainly $\mathrm{Fe}$ oxide and $\mathrm{Fe}, \mathrm{Cr}$ oxide.

Finally, surface spallation was observed on P91 in Figure 4. P91 surface oxide exhibited poor adhesion in general, as flaking occurred during typical handling. P91 exposed to molten salts at $450^{\circ} \mathrm{C}$ had corrosion degree greater than other metal materials. By SEM / EDS analysis shows that mainly has $\mathrm{Fe}$, $\mathrm{O}$ elements and a small amount of $\mathrm{Cr}$ element in region $\mathrm{J}$. The corrosion products of P91 are mainly Fe oxide, the corrosion products were quite similar to 304. 


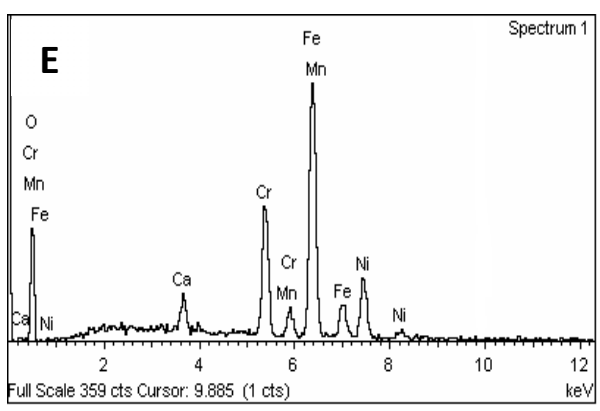

\begin{tabular}{l|ll}
\hline Element & Weight\% & Atomic\% \\
O K & 15.26 & 35.30 \\
Cr K & 16.11 & 12.95 \\
Mn K & 1.84 & 1.40 \\
Fe K & 49.27 & 36.88 \\
Ni K & 17.51 & 12.47 \\
Totals & 100.00 & \\
\hline
\end{tabular}

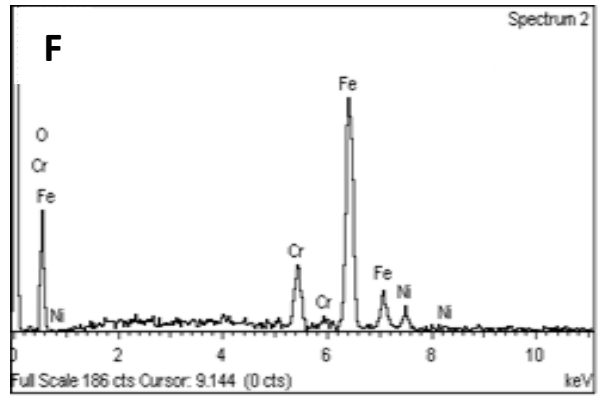

\begin{tabular}{l|ll}
\hline Element & Weight\% & Atomic\% \\
O K & 18.59 & 42.86 \\
Cr K & 9.82 & 7.31 \\
Fe K & 65.06 & 45.52 \\
Ni K & 6.54 & 4.31 \\
Totals & 100.00 & \\
\hline
\end{tabular}

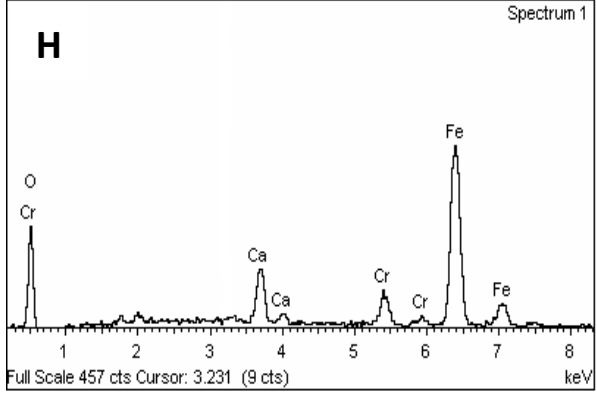

\begin{tabular}{l|ll}
\hline Element & Weight\% & Atomic\% \\
O K & 22.59 & 49.42 \\
Ca K & 7.19 & 6.28 \\
Cr K & 6.52 & 4.39 \\
Fe K & 63.70 & 39.92 \\
Totals & 100.00 & \\
\hline
\end{tabular}

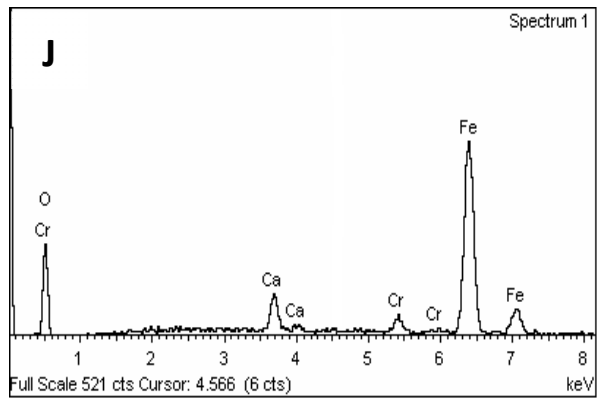

\begin{tabular}{l|ll}
\hline Element & Weight\% & Atomic\% \\
O K & 24.53 & 50.03 \\
Cr K & 3.15 & 2.23 \\
Fe K & 72.32 & 47.73 \\
Totals & 100.00 & \\
\hline
\end{tabular}

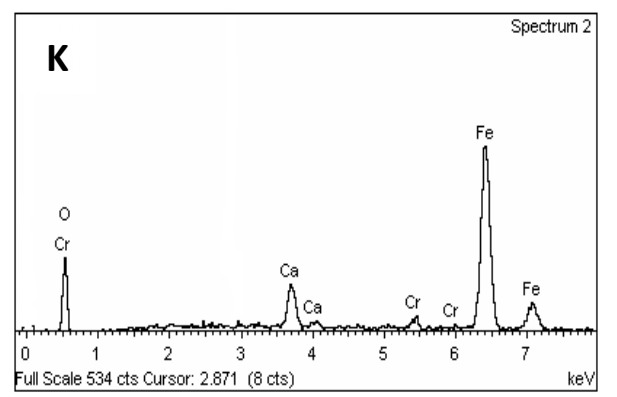

\begin{tabular}{l|ll}
\hline Element & Weight\% & Atomic\% \\
O K & 24.98 & 49.64 \\
Cr K & 2.17 & 1.56 \\
Fe K & 72.85 & 48.80 \\
Totals & 100.00 & \\
\hline
\end{tabular}

Figure 4. EDS X-ray spectra of metal materials in the modified Hitec molten salts at $450^{\circ} \mathrm{C}$ ( $\mathrm{a}, \mathrm{b}, \mathrm{c}, \mathrm{d}$ for region $\mathrm{E}, \mathrm{F}, \mathrm{H}, \mathrm{J}$ and $\mathrm{K}$ in Figure 4, respectively) 


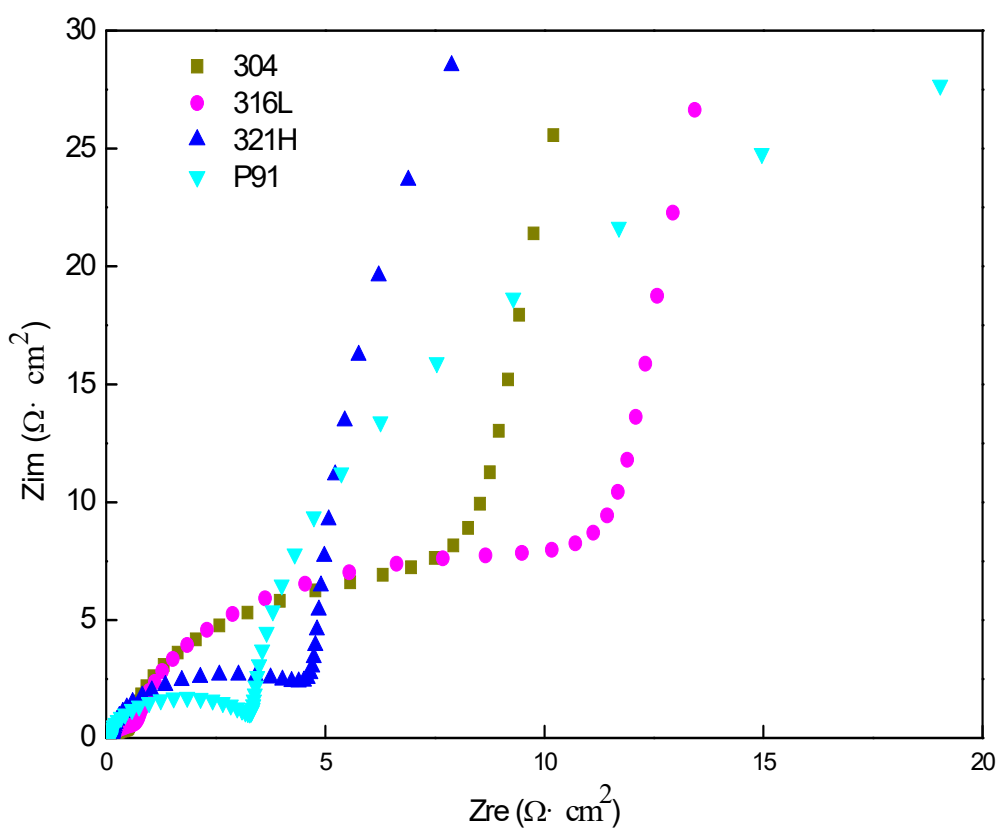

Figure 5. Nyquist plots for 316L, 304, 321H and P91steels in the modified Hitec molten salts at $350^{\circ} \mathrm{C}$.

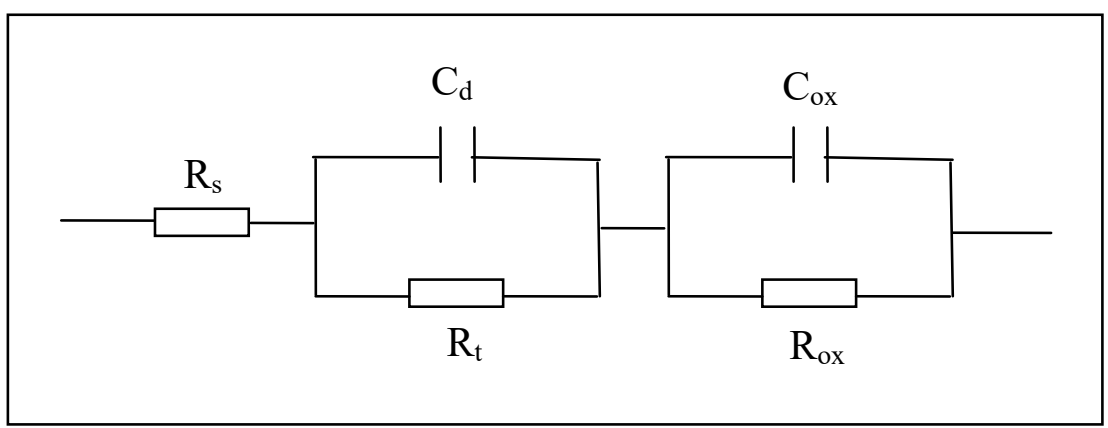

Figure 6. Equivalent electrical circuit for 316L, 304, 321H and P91steels in the modified Hitec molten salts at $350^{\circ} \mathrm{C}$.

Figure 5 showed the Nyquist plots of 316L, 304, 321H and P91steels in the modified Hitec molten salts at $350^{\circ} \mathrm{C}$. As can be seen in Fig. 5, impedance diagrams for 316L, 304, 321H and P91steels were composed of two overlapping semicircles. To interpret these data, an appropriate equivalent circuit is proposed in Fig.6. The Nyquist plots on high frequency and low frequency band of 316L, 304 are larger curvature radius of the circular arc. Other the Nyquist plots on high frequency band of $321 \mathrm{H}$, P91steels are smaller curvature radius of the circular arc, and low frequency band are larger curvature radius of the circular arc. The phenomenon indicated that the anticorrosive properties of $316 \mathrm{~L}, 304$ steels are better than $321 \mathrm{H}$ and P91steels. The Nyquist plots show that anticorrosive properties of metal materials accordance with corrosion kinetics curve of metal materials. 


\section{Summary}

The corrosion kinetics of 304, 316L, 321H, P91 metal material in the modified Hitec molten salts at $450^{\circ} \mathrm{C}$ is also investigated. Under the same condition it was found that $316 \mathrm{~L}, 304$ steels corroded at a rate of 35\% less than P91. Spallation of corrosion products was observed on P91 steel, while no obvious observed on other kinds of stainless steel. Corrosion rates of 316L and 304 slowly increased with temperature. Oxidation mechanisms little varied with temperature. Corrosion products of $316 \mathrm{~L}, 304$ steels observed at $450^{\circ} \mathrm{C}$ were primarily $\mathrm{Fe}$ oxide and $\mathrm{Fe}, \mathrm{Cr}$ oxide. Electrochemical tests were performed by electrochemical measurement work station. The Nyquist plots of metal materials indicated that the anticorrosive properties of $316 \mathrm{~L}, 304$ steels are better than $321 \mathrm{H}$, P91steels. Then the anticorrosive properties of metal materials accordance with corrosion kinetics curve of metal materials. The corrosion rates of metal materials can pad on theoretical basis to speed up concentrating solar power plant.

\section{References}

[1]Cui HT, Yang F. Thermal Storage Technology and its Application. Chemical Industry Press: Beijing, 2004; 8:1-6

[2] Johnson Winford B, Nagle Wesley M. Circulating HTS as a Pilot Plant Heat Transfer Medium. Industrial \& Engineering Chemistry, 1947, 39(8): 971-974.

[3] Mills David. Advances in solar thermal electricity technology. Solar energy, 2004, 76(1): 19-31.

[4] Kamimoto Masayuki, Tanaka Tadayoshi, Tani Tatsuo, et al. Investigation of nitrate salts for solar latent heat storage. Solar Energy, 1980, 24(6): 581-587.

[5] Oró E, Gracia A, Castell A, Farid MM, Cabeza LF. Review on phase change materials (PCMs) for cold thermal energy storage applications. Apply Energy 2012;99:513-33.

[6] Bradshaw Robert W, Goods Steven Howard. Corrosion resistance of stainless steels during thermal cycling in alkali nitrate molten salts. In: Sandia Nat. Lab.; 2001.

[7] Bradshaw Robert W, Goods Steven Howard. Corrosion resistance of stainless steels during thermal cycling in alkali nitrate molten salts. In: Sandia Nat. Lab.; 2001.

[8] Fernández AG, Lasanta MI, Pérez FJ. Molten salt corrosion of stainless steels and low-Cr steel in CSP plants[J]. Oxidation of metals, 2012,78(5-6): 329-348.

[9] Salih SA, El-Masri AN, Baraka AM. Corrosion behaviour of some stainless steel alloys in molten alkali carbonates (I)[J]. Journal of materials science, 2001,36(10): 2547-2555.

[10]Test method of metal corrosion amount and corrosion rate of chemical cleaning for industrial equipment-Gravimetric method, GB/T 25147-2010.

[11] Chatha Sukhpal Singh, Sidhu Hazoor S, Sidhu Buta S. High temperature hot corrosion behaviour of $\mathrm{NiCr}$ and $\mathrm{Cr} 3 \mathrm{C} 2-\mathrm{NiCr}$ coatings on $\mathrm{T} 91$ boiler steel in an aggressive environment at $750 \mathrm{C}[\mathrm{J}]$. Surface and Coatings Technology, 2012,206(19): 3839-3850. 